INSTITUTO DE ENSINO SUPERIOR DE RONDÔNIA - IESUR

FACULDADES ASSOCIADAS DE ARIQUEMES - FAAr

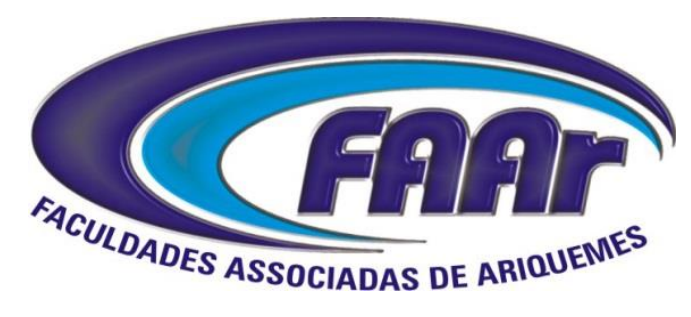

NAIARA FABIOLA SOUZA MAGRIN

A IMPORTÂNCIA DO RELACIONAMENTO ENTRE COMPRADOR E FORNECEDOR NA GESTÃO DE COMPRA E VENDA DO PESCADO EM ARIQUEMES-RO 
NAIARA FABIOLA SOUZA MAGRIN

\section{A IMPORTÂNCIA DO RELACIONAMENTO ENTRE COMPRADOR E FORNECEDOR NA GESTÃO DE COMPRA E VENDA DO PESCADO EM ARIQUEMES-RO}

Trabalho de Conclusão de Curso apresentado como requisito para obtenção do título de Bacharel em Administração Geral do Instituto de Ensino Superior de Rondônia - IESUR/ Faculdades Associadas de Ariquemes - FAAr.

Prof. ํㅜㄹ Orientador: Luís Antônio Vieira Garcia 


\section{A IMPORTÂNCIA RELACIONAMENTO ENTRE COMPRADOR E FORNECEDOR NA GESTÃO DE COMPRA E VENDA DO PESCADO EM ARIQUEMES-RO}

Trabalho de Conclusão de Curso apresentado como requisito para obtenção do título de Bacharel em Administração do Instituto de Ensino Superior de Rondônia IESUR/ Faculdades Associadas de Ariquemes - FAAr.

Defendida em de de

Banca examinadora

Luís Antônio Vieira Garcia

Professor (a)

Professor (a) 
$\checkmark$ Primeiramente a Deus pela força coragem e determinação, nas dificuldades superadas.

$\checkmark$ Aos meus pais que me mostraram que estudar é o melhor caminho. 


\section{AGRADECIMENTOS}

Aos meus pais, Jorge e Enandir, que sempre estiveram presente nessa difícil tarefa.

Aos colegas de faculdade que estiveram presente na partilha de tarefas por difíceis que fossem.

Aos professores pela dedicação, compreensão e paciência, por nos fazer absolver parte de sua sabedoria. 
Escolha um trabalho que goste, e não terás que trabalhar nem um dia na tua vida.

Confúcio, sábio chinês 


\section{RESUMO}

Este trabalho foi desenvolvido com o intuito de descrever a importância do relacionamento entre comprador e fornecedor na gestão de compra e venda do pescado em Ariquemes/RO. Onde teve por objetivo caracterizar essa atividade no município local. Nele será apresentado à importância do comprador e fornecedor na comercialização do pescado e a gestão de compra e venda do produto citado. Enfatiza-se ainda, o conceito de marketing, essa área vem crescendo de forma positiva, apresentando hoje um potencial de crescimento e geração de renda. Com o aumento no consumo do peixe os fornecedores começaram a procura técnica para se manter competitivo no mercado. Tendo como prioridade buscar mais informação, tecnologia e desenvolvimento de qualidade da aquicultura. Com a informação tecnologia os clientes estão se tornando mais exigente procurados alimentos saudáveis e frescos. A pesquisa se caracteriza como bibliográfica com enfoque qualitativo.

Palavras-chave: Comprador e fornecedor. Gestão de compra e venda. Marketing. 


\begin{abstract}
This work was developed with the purpose of describing the importance of the relationship between buyer and supplier in the purchase and sale management of fish in Ariquemes / RO. The purpose of this study was to characterize this activity in the local municipality. In it will be presented to the importance of the buyer and supplier in the commercialization of the fish and the management of purchase and sale of the cited product. It also emphasizes the concept of marketing, where this area has been growing positively, presenting today a potential for growth and income generation. With the increase in fish consumption the suppliers started looking for techniques to stay competitive in the market. Having as priority to seek more information, technology and aquaculture quality development. With the information technology the customers are becoming more demanding looking for healthy and fresh food. The research is characterized as a bibliographical with a qualitative approach.
\end{abstract}

Keywords: Buyer and supplier. Purchase and sale management. Marketing. 
1. INTRODUÇÃO

2. A IMPORTÂNCIA DO COMPRADOR E FORNECEDOR....................................11

2.1 RELACIONAMENTOS ENTRE COMPRADOR E FORNECEDOR .....................12

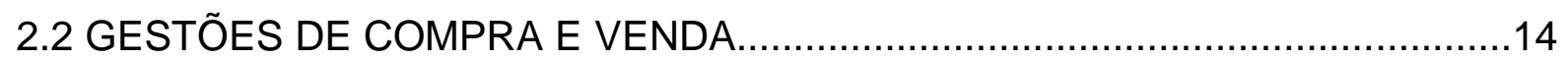

2.3 COMPRAS/VENDAS: FUNÇÕES E IMPORTÂNCIA.......................................15

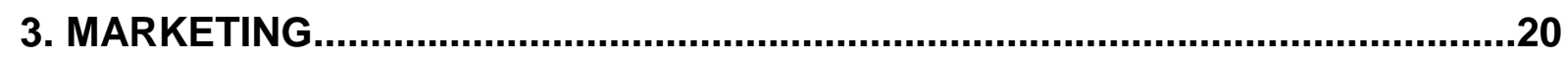

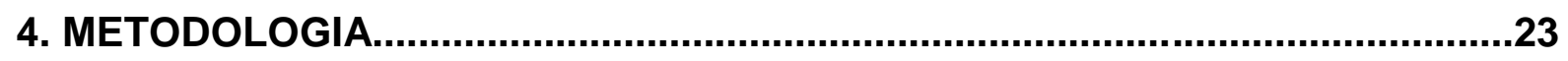

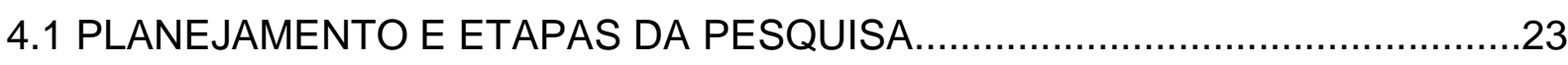

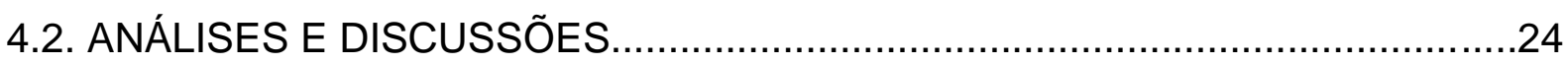

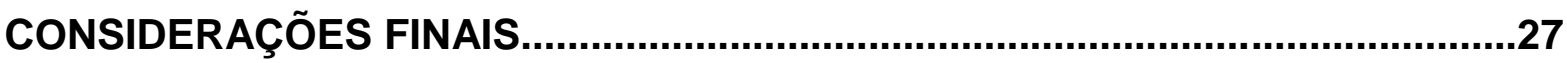

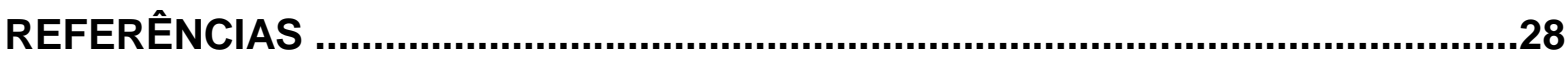




\section{INTRODUÇÃO}

Frente à necessidade de se manterem competitivas no mercado, as organizações devem buscar constantemente a melhoria dos seus processos para serem capazes de se adaptar as novas condições do mercado. Uma forma de atingir este objetivo é através do gerenciamento de suas cadeias de fornecimento. Desta forma, o presente trabalho teve como abordagem a importância do bom relacionamento entre comprador e fornecedor na gestão de compra e venda do pescado em Ariquemes-RO.

A satisfação do cliente destaca-se como ferramenta fundamental e indispensável para o sucesso dos negócios e o bom relacionamento entre comprador e fornecedor.

Utilizando de estratégia de marketing os produtores de peixes começaram a focar no mercado consumidor, tendo como objetivo aumenta o número de cliente. Os consumidores estão cada vez mais exigentes e com isso busca informação para decisão de compra.

Devido o aumento do consumo do pescado a competitividade aumentou e os gestores começaram a entender e melhorar o relacionamento com seus fornecedores. Melhorando a administração de compra e venda do peixe no município local.

Objetivos são apresentados o método de trabalho através da caracterização do tipo de pesquisa, bem como da descrição das etapas, técnicas e ferramentas empregadas para alcançar os objetivos propostos. As limitações do trabalho são estabelecidas e o capítulo é encerrado com o cronograma em que se pretende organizar a dissertação.

O trabalho é estruturado em 4 (quatro) capítulo. O primeiro trata-se da abordagem sobre o tema a importância do relacionamento entre comprador e fornecedor na gestão de compra e venda do pescado em Ariquemes/RO, pois, o fornecedor, por consequência, passa a ter responsabilidade por uma parcela de satisfação do cliente em relação ao produto ou serviço. Tendo em vista a importância da gestão de compra e venda para competitividade do mercado atual. 
Referencial teórico no capítulo 2 aborda a tarefa do marketing e sua dimensão em criar, promover e fornecer bens e serviços aos clientes. Orientado para a satisfação dos desejos e necessidades dos consumidores locais, e a partir de sua compreensão, ofertar produtos e serviços com objetivo de gerar mais lucros às empresas e tornar os consumidores satisfeitos. Mostrando o plano estratégico do projeto.

No capítulo 3, metodologia, que fornece o método utilizado da pesquisa, processo de elaboração tendo como objeto de estudo a análise descritiva, a pesquisa é de natureza bibliográfica com enfoque qualitativo e coleta de dados. $\mathrm{O}$ âmbito desta pesquisa está ligado ao relacionamento do fornecedor e comprador, administração de compras e venda a importância do peixe na alimentação, comercialização do pescado e Marketing.

O 4 capítulo coloca-se em prática a importância do relacionamento entre comprador e fornecedor do pescado, mostrando que desenvolvida corretamente torna-se uma atividade aliada a sustentabilidade, já que substitui a pesca extrativa, contribuindo com a preservação do meio ambiente onde cria um ponto positivo para aquicultura local.

Apresentará as conclusões mais importantes deste trabalho. Também serão listados os tópicos que não foram abordados, mas que são considerados promissores para investigações futuras. 


\section{A IMPORTÂNCIA DO COMPRADOR E FORNECEDOR}

Para que a transação comercial entre comprador e fornecedor se torne harmoniosa, é necessário que a colaboração entre empresas e fornecedor seja cultivada, promovendo uma convivência duradoura e promissora facilitando o relacionamento trazendo governança.

No estudo foram analisados quatros fatores importantes para obter esse objetivo, sendo eles: a confiança, a inovação, o foco no cliente e a satisfação. Umas das relações mais utilizadas na comercialização de produto ou serviço e a confiança, para que haja essa harmonia entre o processo de compra e fornecimento, e necessário que tenha a confiabilidade em vários aspectos.

Confiança é o ato de confiar, para Friman et al (2002) é crer na capacidade de cumprir as promessas e as obrigações contratuais. Mostra confiança entre as parte e colabora para o melhor desempenho.

A confiança e a troca entre parceiros mostrando a característica de relacionamento inovador. Lee et al (2001). A inovação vem se tornando uma ferramenta valiosa para aqueles que buscam se torna competitivo no mercado. A qualificação e diferenciação no produto ou serviço possibilitam que o fornecedor obtenha destaque no mercado competitivo.

As empresas que inovam obtém vantagem em ralação às demais, podendo alcança novos conhecimentos, novos mercados, aumenta seu lucro e agrega valor nos seus produtos.

O investimento na inovação vem fidelizando cliente e criando uma imagem positiva e trazendo vantagem de venda e lucros para as empresas.

A inovação é o instrumento para empreender, explora mudanças e oportuniza negócios diferentes. Drucker (1985)

A inovação é, mais do que nunca, um diferencial competitivo para as empresas que buscam mudanças e oportunidades de êxito. Os clientes são a razão da organização, para que as empresas tenham a existência no mercado ela precisa foca no cliente. 
Com o acesso ás informações comerciais os clientes estão mais exigentes, com isso não baste ter apenas foco no cliente, mais sim analisar o cliente. Mckenna (2002).

A satisfação do cliente vem sento um conceito que tem semelhança com a qualidade. Pois, quando um produto ou serviço preenche, ou excede a expectativa do cliente, este fica sempre satisfeito. Este conceito de satisfação tem semelhanças com o de qualidade, uma vez que ambas estão intimamente relacionadas e dependentes da percepção do cliente.

Segundo Slongo (2004), Satisfação dos clientes é a relação dos serviços prestados pela empresa é a consequência da credibilidade e da confiabilidade. Já a insatisfação é a falta de comunicação e à demora de informações.

[...] Um cliente tem vários níveis de satisfação. Se o produto atingir a expectativa, ele ficara satisfeito. Se a expectativa for abaixo do desempenho desejado ele ficará insatisfeito. O produto tem que exceder essas expectativas, para que o cliente fique satisfeito ou encantado. (SCHMITT, 2004, p. 23).

Para que haja a satisfação nos negócios. Os clientes esperam a reciprocidade de compromisso entre compradores e fornecedores.

\subsection{RELACIONAMENTOS ENTRE COMPRADOR E FORNECEDOR}

Para Claro (2004), a confiança e as informações, são primordiais no relacionamento entre compradores e fornecedores, pois, segundo Ford et al. (2003), as alianças estratégicas entre compradores e fornecedores estão se tornando cada vez mais comum, isso se dá através da obtenção de vantagens competitivas.

A confiança e ressaltada como sendo a mais importante no desenvolvimento da colaboração. (ANDERSON; NARUS, 1990; KIM, 1999). 
Para Heide; John (1992), A mudança de transação de mercado e a ação conjunta de planejamento e o resultado de definição de metas envolvendo comprador e fornecedor influenciando positivamente em seus negócios.

E importante ressalta que a confiança da credibilidade para ambas as partes diminuem a obrigação e deveres que são normalmente encontradas em contrato.

Segundo (LUSCH; BROWN, 1996) o sucesso de uma empresa depende da consolidação e relacionamento na resolução de um problema. Sento um modo importante de procura saber a causa e sua solução em algumas falhas técnicas ou situação indesejada.

As empresas que apresenta ações conjuntas pode produzir melhores resultados que as empresas que opta por serem isoladas (ANDERSON; NARUS, 1990).

A confiança na relação entre comprador e fornecedor, e importante para troca de informações, pois pode ser considerada como base relacional para o decorrer das ações conjuntas (ZAND, 1972).

Quanto maior a confiança de um comprador em seu fornecedor, mais o comprador se envolver á em ações conjuntas com o fornecedor. As empresas que buscam crescer juntos com seus colaboradores, tende atingir seus objetivos com mais sucesso. (CLARO, 2004).

A confiança deve ser conquistada por comunicação, trocas de ideias e informações sobre o objetivo entre ambos, as organizações estão desenvolvendo lideres, gestores, empresários e colaboradores com a função de conquistar cliente.

As organizações incentivam os relacionamentos colaborativos com fornecedores, com o objetivo de incentivar as empresas a contribuir mais com os fornecedores.

Pesquisas apontam que relacionamentos com fornecedores significa mais do que realizar uma boa compra, além de entregar produtos nos prazos certos e com preços acessíveis, os mesmos podem realizar muito mais, realimentando a confiança neles depositados, investindo em ativos e respondendo as ações conjuntas dos compradores (CLARO, 2004). 


\subsection{GESTÕES DE COMPRA E VENDA}

A gestão de compras é uma atividade fundamental para relação do comércio.

Segundo Francischini; Gurgel (2002) a centralização da compra traz um aspecto positivos com relação aos preços médios de aquisição, mas dependendo do tipo de compras e aconselhável que a aquisições seja a descentralizada.

A gestão de vendas analisa os clientes, priorizando 0 atendimento para melhor atender, tanto no pré-vendas como no pós-vendas. O gestor deve estar sempre atualizando os dados sobre as saídas dos materiais, sabendo a quantidade e quando são usados ou vendidos a fim de tornar satisfatório o produto ou serviço.

Em análise de mercado, a função das compras passou a ser indispensável para gestão de recurso material de uma empresa. Toda empresa deve esta atenta na compra, procurando sempre satisfazer sua necessidade, priorizando atender a necessidade do período (DIAS, 1993).

O setor de compras está relacionado com nível de estoque. A ele competiu o equilíbrio na quantidade de materiais a serem comprados, tendo como objetivo reduzir custo e melhora os lucros. Assim a gestão de compras tem uma função importante de cuida para que os níveis de estoque da empresa estejam sempre equilibrados.

Segundo Pozo (2010) a elevação de custos pode acarretar atrasos de produção, prazos, desempenho e preços, causando consequência e insatisfação do cliente.

DIAS (1993) para obter um volume de vendas e um perfil competitivo, seguida de lucros satisfatórios, devem-se sempre buscas custos, podendo concluir que os objetivos básicos são. a) Obter um fluxo contínuo de suprimentos com o intuito de atender aos programas de produção; b) Coordenar o fluxo que seja aplicado um pouco de investimento que afete o sistema operacional da empresa; c) Comprar materiais e insumos com preços baixos, obedecendo a padrões de qualidade e quantidade determinados, e d) Procurar em uma negociação justa as melhores condições para empresa, especialmente em condições de pagamento.

Um dos requisitos mais importante para organização é planejar, controlar os estoques, desde a matéria-prima até a entrega ao cliente do produto acabado. 
Antigamente muitas empresas tratavam o controle de suprimentos como secundário e quando algumas delas paravam de funcionar por falta de estoque, que se davam conta da importância de planejar e controlar o fluxo de materiais de forma correta. O estoque exige uma observância em cada um dos níveis de planejamento por isso faz parte do planejamento de produção.

[...] Para obter um nível de estoque adequado as empresas necessita compra com qualidade, onde comprando bem e de forma adequada as empresas estarão reduzindo custo. $\mathrm{O}$ comprador deve analisar o fornecedor, verifica suas instalações, potencialidade e produtos, observando seu balanço e obtendo sempre cadastro atualizado. Dias (1993)

A gestão de estoque visa aumentar o controle de custos e melhorar a qualidade dos produtos guardados na empresa. Definindo a qualidade de estoque de cada produto da empresa, entretanto, só é possível defini-la a parti da previsão da demanda de consumo do produto.

\subsection{COMPRAS/VENDAS: FUNÇÕES E IMPORTÂNCIA}

A função de compras é responsável pelo fluxo dos materiais na empresa. Pelo seguimento junto ao fornecedor, e pelo compromisso da entrega. Os prazos de entrega e de suma importância para departamento de produção e vendas, mas a função compra pode reduzir o número de problemas para ambas as áreas, além de adicionar lucros para empresa.

Os gestores de compras fazem uma ligação importante entre a empresa e seus fornecedores. O Departamento de compras de uma empresa exerce a função e responsabilidade de estabelecer o fluxo dos materiais junto ao fornecedor. Com a importância de desenvolver e manter boas relações com os fornecedores e desenvolver fornecedores potenciais.

Para Chiavenato (2005), o setor de compras tem a finalidade de aquisição de materiais, componentes e serviços a fim de suprir as necessidades da empresa, bem como o acesso direto a informação vinda da alta gerência para que passe atuar 
forma estratégica. A falta de comunicação direta pode impedir que as informações sobre o mercado seja trabalhada pelo órgão de compras, que contribui diretamente com a ligação entre empresa e seu ambiente externo.

O setor de compra ele e considerado um fator de lucro e não somente de custo, pois, quando bem administrado ele traz beneficio de economias, lucros pra organização e vantagens competitivas. Toda empresa bem administrada produz, vende e compra melhor. O setor de compras desenvolve e mantém fontes de suprimentos adequados para atingir sua finalidade.

O órgão de compras não apenas importante para manter a necessidades de insumos e materiais da empresa como também garante a qualidade assegurada, economia, prazos e por fim a lucratividade.(CHIAVENATO, 2005).

Ainda, segundo Chiavenato (2005), o setor de compras depende de cada ramo e necessidades de materiais. Empresas industriais, grandes lojas, supermercados e empresas de serviços organizam suas compras conforme os materiais a serem comprados, as exigências do processo produtivo, as características do mercado fornecedor e outros fatores preponderantes.

Para a organização, compras é o conhecimento entre fornecedor e a empresa. Contudo, a busca por novos fornecedores para que os insumos estejam na organização no tempo certo, permite concluir que a função compra tem um papel estratégico e de grande importância para as organizações.

A atividade de compras envolve um ciclo de etapas que necessariamente devem ser cumpridas, cada qual no seu tempo, pois, o ciclo é acionado cada vez que haja a necessidade de adquirir algum material. Pois a reposição desses materiais acorre repetitivamente, isto porque o processo pode ser aperfeiçoado com objetivo da eficiência cada vez maior. (CHIAVENATO, 2005).

A cadeia de suprimentos está relacionada a bens ou produtos que uma organização mantém para atender a uma determinada demanda futura. A importância do suprimento se estende a todas as empresas, independentemente do ramo de negócio toda empresa terá de constituir estoques, mesmo que seja para materiais de uso e consumo. (SLACK, 2002. p. 415). 
Com o funcionamento correto da gestão de compras as contratações entre fornecedores são garantida. Assim podendo obter um menor custo possível com a qualidade superior.

O objetivo da gestão de compras e torna-se necessário por diversos fatores, dentre os quais o valor investido, a necessidade de dimensionar o estoques adequado, garantir qualidade, evitar estoque em excesso e faltas, garantir a integridade dos materiais. A área de compras não é um fim em si próprio, mas uma atividade de apoio fundamental ao processo produtivo, suprindo-o as necessidades de materiais. (POZO,210,p.133).

\footnotetext{
"Portanto, o investimento correto na gestão de compras minimizando as necessidades de capital investido". Para Dias (1993)
}

Dentro da visão de vendas, cujo foco está numa comunicação qualificada como parte essencial de uma venda, é importante reconhecer que a comunicação entre vendedor e cliente e muito importante. Pois a tendência é que o vendedor deixe de ser apenas vendedor, e passe a ser o comunicador do desenvolvedor de negócios, aquele que entende pensa no processo de negociação, enxerga a empresa, o cenário competitivo, debate sobre a oferta e procura, reflete sobre a estratégia, entende do que vende, acredita no que vende, passa credibilidade e segurança ao cliente.

Para Kotler (2000), os vendedores são os representantes da empresa perante o cliente, com isso e interessante que a empresa invista em alguns pontos de desenvolvimento de força de vendas. A definição de especialização representa uma decisão estratégica por meio da qual, é possível obter a vantagem de diversificar o risco da empresa.

Portanto, a importância de uma gestão estratégica da área de vendas, em especial da força de vendas, que deve ser qualificada e capacitada para atender as demandas de mercado onde cada cliente é único, diferente, cada vez mais exigente e em constante evolução.

Segundo Castro; Neves (2008) vendas e a previsão de demanda onde se avalia a escolha dos vendedores contratados, definição de territórios, especialização por tipo de cliente, entre outras decisões são informações importantes a ser consideradas. 
O vendedor esta diariamente em contato com o mercado, assim ele pode perceber a ação a ser tomada e os preços da concorrência, os resultados das promoções e propagandas que a empresa desenvolve as falhas e desejos dos clientes não correspondidos, assim opinando dentro da organização de vendas novas atitudes e estratégias a serem tomadas. (LAS CASAS, 2005).

Para Las Casas (2004), a estrutura organizacional de uma empresa deve seguir o princípio básico de que "a forma deve acompanhar a função" e, além disso, contribuir para a manutenção de uma relação harmoniosa entre os departamentos, favorecendo a colaboração e interação através do fluxo de informações entre ambos.

Ainda, segundo Las Casas (2005), a estrutura da administração de vendas é focar no cliente, e tomar quais são suas necessidades, o que a empresa pode estar fazendo para atendê-lo, tanto no pré-venda quanto no pós-venda, tornando assim um cliente fiel e satisfeito com a empresa. Além disso. A organização contribuir para a manutenção de uma relação harmoniosa entre os departamentos, favorecendo a colaboração e interação através do fluxo de informações entre ambos.

Para se obter sucesso da gestão de vendas e recrutamento e necessário a seleção, treinamento, supervisão, pagamento e motivação à medida que as tarefas se aplicam a admiração de vendas.

\footnotetext{
"Selecionar vendedores seria simples se já estive por conhecimento os gosto de cada cliente. Um bom começo é perguntar aos clientes que características eles preferem em vendedores. Muitos dizem que querem que o vendedor seja honesto e confiável, que conheça o produto e as atividades do setor e que seja prestativo. A empresa deverá procurar vendedores habito as essas seleções." (KOTLER, 2000)
}

Segundo Kotler (2000), os vendedores servem como uma espécie de elo pessoal entre os clientes e a empresa. $O$ vendedor representa a empresa para muitos dos seus clientes, pois é ele quem leva as mais importantes informações sobre o cliente a empresa. Para ser um bom vendedor tem que primeiro conhecer seu produto e conhecer seus compradores, é interessante que a empresa tenha táticas de vendas e pessoas capacitadas para negociarem, pois além de venderem o produto, o vendedor estará representando e passará a imagem da empresa a seus 
clientes e a maioria das vezes o vendedor é a única ponte que liga o cliente à empresa.

Dominar essas habilidades, não é o suficiente. Para Kotler (2000), os profissionais de vendas têm por obrigação saber analisar dados de vendas, saber medir o potencial do mercado em questão, desenvolver estratégias e principalmente planos de marketing, desenvolver ainda suas habilidades de análises de mercado, pois, as empresas acreditam que as forças de vendas se tornam mais efetivas ao longo prazo por entenderem tanto de marketing quanto de vendas, sendo esse 0 diferencial de uma empresa em potencial.

Segundo Las Casas (2004), umas das estratégias de vendas estão no treinamento de seus vendedores. Buscando objetivar maior retorno desse investimento feito na contratação o mais rápido possível.

Os treinamentos em vendas são feitos com relação a características de produção, dos clientes, da empresa, do mercado e sobre técnicas de vendas. (CASTRO; NEVES, 2008).

A visão tradicional que norteia a gestão de venda deve ser dentro da realidade e características dos mercados-alvo em que atuam e na posição almejada. A grande parte das organizações tem a preocupação com o volume de vendas gerado, cabendo ao departamento de marketing à tarefa de apurar a estratégia e rentabilidade. 


\section{MARKETING}

Marketing e a diversificação dos produtos no mercado consumidor. Por esse fator o consumidor tem varias opções de escolha na compra do produto ou serviço. Além disso, quando o fornecedor diferencia seu produto da concorrência ele ganha vantagem competitiva. Isto se dá através da diversificação dos produtos oferecendo influenciando o consumidor para o consumo.

Marketing é a satisfação do consumidor em forma de benefício. Tendo como atividades que orientam os fluxos de bens e serviços do local onde são gerados até os consumidores finais, para Kotler (2000) é um processo social no qual as pessoas obtêm aquilo que necessitam e desejam com a criação, oferta e livre negociação de produtos ou serviços.

A análise do posicionamento é indispensável para avaliar o destaque da imagem da empresa. A ação de projetar o produto e a imagem da organização com a intenção de se posiciona de uma forma diferenciada na escolha do publico alvo.

E fundamental para marketing o desenvolvimento estratégico de uma empresa, para definir o posicionamento de mercado deve-se entender sobre a empresa, marca e a necessidades do consumidor. Saber diferencia dos concorrentes e desenvolver um mercado bem definido. Kotler (2000)

Segundo Peter; Donnelly Jr (2013), o conceito de marketing é gerenciar os gestores para verifica a necessidades dos clientes, logo, elabora o produto e serviços que satisfaçam as necessidades do consumidor. Com isso, as empresas devem focar na criação de relacionamento de longo prazo com o cliente, gerando satisfação do cliente e consequentemente maior lucro para a empresa.

Marketing tem a função básica de identificar as necessidades e desejos dos clientes e desenvolver seus produtos de forma satisfatória. Tendo como prioridade uma visão produtiva e analisar os mercados alvos. Determinando o poder do atendimento do consumidor, planejamento de produtos e serviços e propagandas para satisfazer o publico alvo. Maso (2010) 
As principais funções de marketing marketing: a) a gerência do produto, onde é feito o processo de acompanhamento desde as pesquisas iniciais, design, fabricação até chegar aos mercados; b) a definição do preço, sua estratégia é definir a autossuficiência de um determinado produto, a fim de considerar seus rendimentos de lucros à empresa, no entanto, não pode ser tão alto que desestimule a venda e nem tão baixo que deprecie o produto, fazendo o cliente acreditar que tem algo de errado nele, geralmente é feito uma análise dos produtos concorrentes, onde se paga o preço e recebe o beneficio dele; c) a distribuição, isso depende da forma como é feita a venda, normalmente são o atacado, o varejo e as vendas industriais; d) a publicidade, essa é uma das principais técnicas do marketing, onde se cria e desenvolve ou até mesmo muda os hábitos do consumidor, fazendo com que ele tenha uma visão diferenciada e positiva de determinado produto com o concorrente; e) vendas, é o contato direto entre o comprador e o vendedor, este deve usar técnicas que envolvam o cliente de tal forma que ele comece a dar preferência a essa empresa e não à concorrente, tornando uma imagem positiva da empresa e do produto oferecido. Kotler (1994),

Segundo Kotle; Armstrong (2004) marketing é importante para o sucesso da organização, independente do seu porte, com ou sem fins lucrativos. O Marketing vai além do que está exposto aos olhos, está em jornais, revistas, meios de comunicações, oferta em internet e campanhas diversas, por trás do marketing há sempre uma rede de pessoas e atividades que competem pela sua atenção e seu dinheiro.

Atualmente o marketing e entendido como a satisfação e necessidades, desejos dos clientes e não mais como um efetivado de vendas. Se o profissional de marketing entender as necessidades dos consumidores ele desenvolve um produto que corresponde às expectativas do cliente e agrada facilmente o consumidor na questão de valor e bom preço. (KOTLER; ARMSTRONG, 2004).

Inicialmente, o marketing estava mais relacionado com a transferência de bens e serviços. Posteriormente, 0 conceito de marketing relativo à satisfação dos desejos e das necessidades dos consumidores passou a ser ampliado e aplicado também em outras áreas como política, turismo [...] (LAS CASAS, 2006, p.9). 
O Marketing desempenha a função de fora pra dentro, com base em atender as necessidades e as expectativas do cliente. $O$ relacionamento entre empresas e clientes passa a ser importante para o sucesso da organização, pois é ele que trabalha nas estratégias focadas nas necessidades e satisfação dos clientes, sempre conquistando e mantendo os mesmos. 


\section{METODOLOGIA}

A elaboração desta pesquisa é de natureza bibliográfica com enfoque qualitativa, tendo como objeto de estudo a análise descritiva na importância do relacionamento entre compradores e fornecedores na gestão de compra e venda do pescado município de Ariquemes/RO. O âmbito desta pesquisa está ligado na forma de como é realizada a compra e a venda do pescado em torno município local.

\subsection{PLANEJAMENTO E ETAPAS DA PESQUISA}

Esta pesquisa foi conduzida conforme as etapas ilustradas no quadro abaixo: Quadro 01 - ETAPAS DA PESQUISA

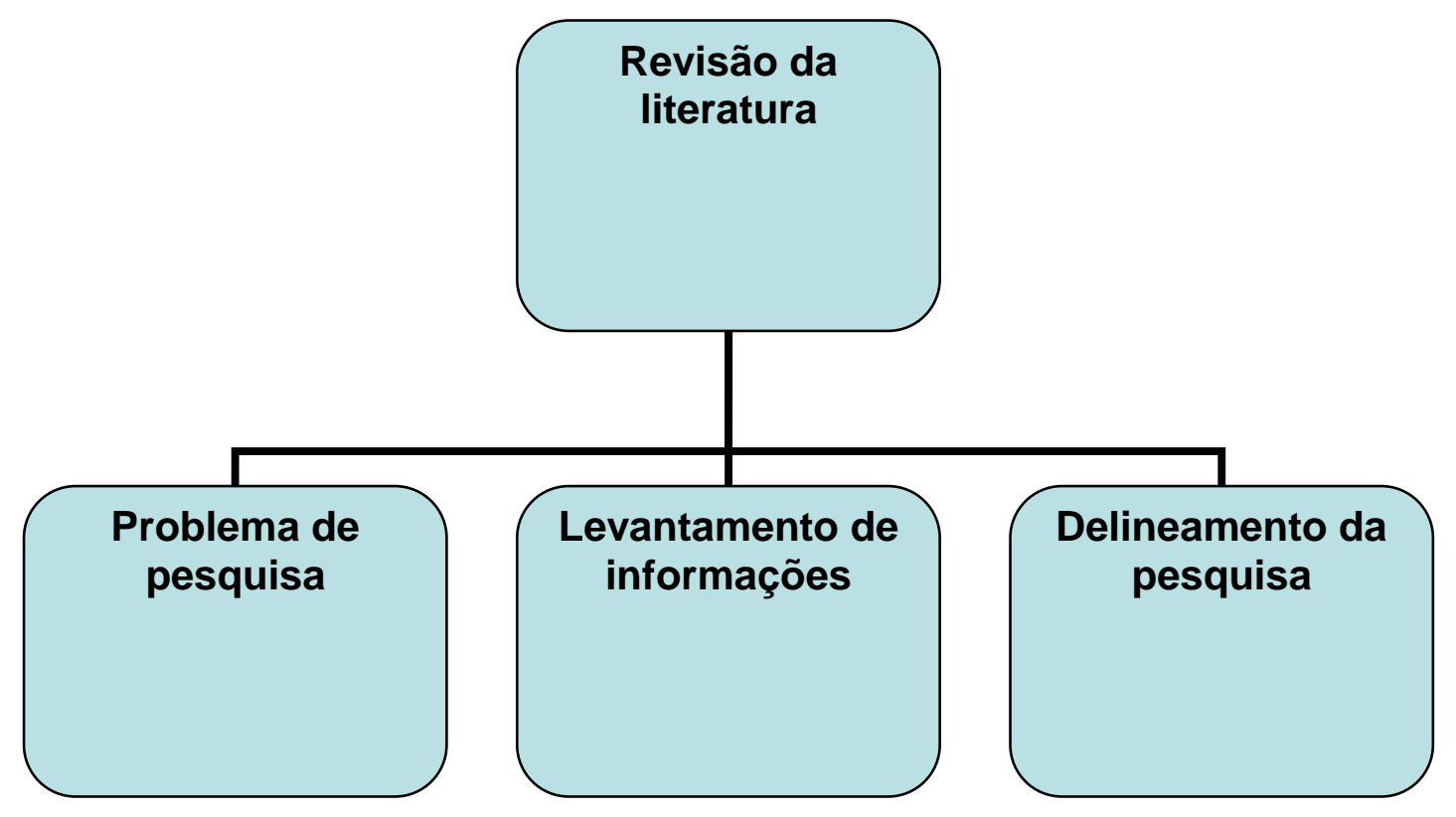




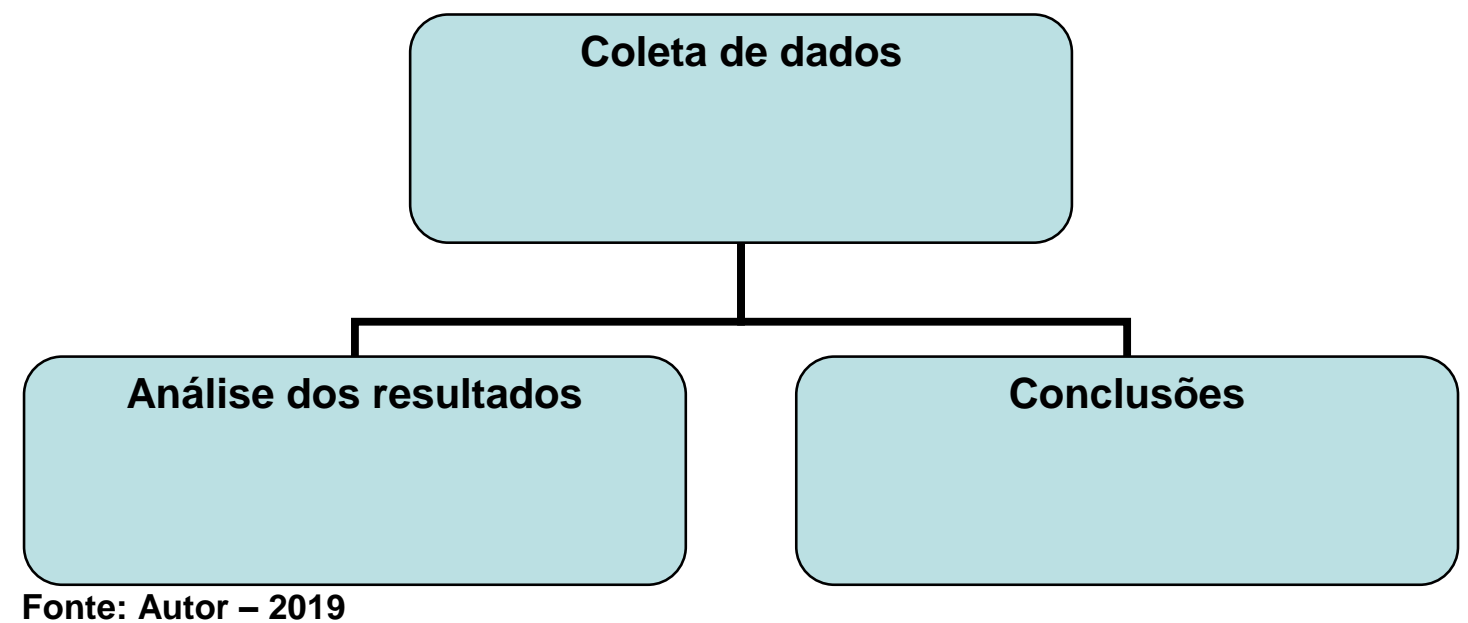

As etapas da pesquisa, conforme ilustra o quadro acima foram acontecendo conforme o desenvolvimento do trabalho em si, em primeira mão houve a revisão da literatura disponível para se determinar qual seria o foco do estudo em questão, neste caso, o problema de pesquisa. Em seguida foram feitos os levantamentos de informações juntamente com o delineamento da pesquisa.

Com todos esses dados em mãos, a partir de uma diversidade de literaturas pesquisadas, houve a coleta e tabulação do referidos dados, e através das análises dos resultados chegaram-se as conclusões finais.

\subsection{ANÁLISE E DISCUSSÕES}

A busca por um estilo de vida mais saudável faz parte cada vez mais da rotina da população. $O$ interesse por alimentos que engloba uma maior qualidade de vida vem aumentando, e isso se reflete também no mercado consumidor.

O peixe é considerado um dos alimentos importante para prevenção de doenças. Graças à sua enorme concentração de nutrientes, vitaminas e proteína. $\mathrm{O}$ consumo do peixe é muito importante, principalmente na infância, pois, contem nutrientes essenciais na fase de desenvolvimento.

O setor da piscicultura está em amplo crescimento, pois, o peixe e um alimento saudável e de fácil preparo, podendo ser preparado de diferentes maneiras e combinações de ingredientes que complementa seus benefícios. 
O consumo do pescado fresco vem se destacando, pois essa modalidade possui um recebimento favorável no mercado quando ele está na sua forma in natura, ao contrário da grande maioria dos outros produtos alimentares que exigem conservantes, corantes que prejudicam a saúde humana.

A piscicultura é uma das áreas da aquicultura, onde o objetivo é a criação de peixes, podendo ser para vendas ou para consumo. A criação de peixes tem que ser gerenciada com técnicas e manuseios corretos para facilita a vendas e consumo, os sistemas mais utilizados é em viveiros escavados e em tanques-rede. Conforme as técnicas aplicadas pelo piscicultor, à criação de peixes pode apresentar grande interesse sócio econômico, em função da sua rentabilidade Filho (1977).

A piscicultura vem crescendo muito no Brasil devido o seu rápido retorno ao capital investido. O ramo da piscicultura deve ser estudado antes de ser explorado, pois a falta de noção de como criar o peixe pode trazer prejuízo. O piscicultor deve ter conhecimento para ter um bom lucro e obter um produto de qualidade.

Para Ostrensky; Boeger (1998), a piscicultura tem todo um processo para o seu cultivo. O produtor precisa saber colocar ração de forma adequada, deve-se ter conhecimento e técnicas para se criar corretamente os peixes no tanque, controla o $\mathrm{PH}$ da agua, os produtos químicos, assistência técnica, e fazer um estudo de mercado para que assim os compradores tenha um produto de qualidade. No Brasil a piscicultura é desenvolvida principalmente por pequenos produtores, que consideram essa atividade como uma forma de completar a renda da família.

Ao inicia o cultivo de peixe o produtor deve saber qual a espécie exigida pelo mercado, pois será este o produto a ser comercializado. Outro aspecto também interessante antes de iniciar a piscicultura é saber o quanto irá investir e o quanto pretende produzir em sua propriedade (OSTRENSKY; BOEGER, 1998).

A piscicultura é uma atividade que envolve desde a escolha da espécie até o local e valor da venda. O Município de Ariquemes vem tendo uma ótima fonte de renda com a criação de pesca comercial. $O$ pescado vem se tornando um atrativo econômico para os produtores rurais, especialmente aos da agricultura familiar devido à criação não depender de grandes áreas. 
A aquisição do pescado pode acontecer de varias formas, aquela em que o fornecedor procura o comprador para informar que possui o produto já em condições de venda pronta para a despesca, outra forma é aquela em que o comprador vai até o produtor em busca do pescado com a intenção de saber se o produto já está no ponto de venda, ou seja, se o produto seguirá os quesitos necessários que satisfazem as exigências do consumidor final.

E fundamental para organização entende seu consumidor e desenvolver técnicas que prioriza os clientes na organização, já que é ele o fundamento para o crescimento e desenvolvimento do empreendimento.

Os clientes estão mostrando maior sensibilidade em relação ao preço em sua busca por valor e também a forma de compra casada, onde o comprador possui os maquinários adequados para a confecção dos tanques de peixes e este receberá seus serviços de hora máquina em longo prazo, tendo como pagamento o próprio peixe criado pelo vendedor.

A transação de venda do peixe segue um rito de confiança, já que tudo e combinado com antecedência, o representante de compra que analisará se o produto está realmente no ponto de venda, sendo feito uma coleta aleatória, por amostragem onde serão observados todos os quesitos necessários. No fator quantidade, é valorizada a confiança na palavra dada pelo vendedor para se programar a despesca com dia e hora certa.

Para que o pescado seja de qualidade ele tem que ser retirado da represa com algumas técnicas e habilidades, como não dar ração no dia da despesca, pois pode prejudica a estrutura do produto ate chegar ao consumidor final, deverá abaixar a agua da represa para facilita o manejo da despesca. Todo esse procedimento é feito após o combinado, onde a reciprocidade da confiança está em primeiro lugar. 


\section{CONSIDERAÇÕES FINAIS}

A necessidade de atender que as preferencias do consumidor jamais termina a partir de um único estudo, principalmente quando se trata de um tema pouco explorado como a compra e venda do pescado e seus benefícios na saúde humana. $\mathrm{O}$ consumo de carne de peixe se mostrou importante na dieta e na economia do município de Ariquemes/RO.

Com o conhecimento teórico e pratico o produtor de peixe vem de destacando e mostrando mais qualidade no seu produto, tendo como funcionamento o aumento de venda no mercado local. Com esse conhecimento o produtor vem trabalhando com tecnologias e combinações que amplia corretamente sua forma de administrar as imensas cargas de trabalho e de dedicação no seu dia-a-dia.

Conclui-se que pondo em pratica os fatores de relacionamento entre compradores e fornecedores do pescado, surgem muitas oportunidades para quem pretende trabalha com essa cadeia de produção, com essa vantagem o consumidor se beneficia e a pesca extrativa diminui, contribuindo com a preservação do meio ambiente e criando um ponto positivo a favor do marketing da aquicultura local. 


\section{REFERÊNCIAS}

ANDERSON, E.; WEITZ, B. Determinants of continuity in conventional industrial channel dyads. Market Science, v. 8, n. 4, p. 310-323, 1989.

ANDERSON, J. C.; NARUS, J. A. A model of distributor firm and manufacturer firm working partnerships. Journal of Marketing , v. 54, n. 1, p. 42-58, 1990.

CASTRO, Luciano Thomé; NEVES, Marcos Fava. Administração de Vendas Planejamento, Estratégia e Gestão. Editora Atlas. São Paulo, 2008.

CHIAVENATO, Idalberto. Administração de Materiais: Uma abordagem Introdutória, Rio de Janeiro: Elsevier Editora Ltda, 2005.

DIAS (1993, P. 23) A IMPORTÂNCIA DA GESTÃO DE ESTOQUES

CLARO, Danny Pimentel; CLARO, Priscila Borin de Oliveira. Artigo - Gestão de operações e Logística: Gerenciando Relacionamentos Colaborativos com Fornecedores, 2004.

DIAS, Marco Aurélio P., Administração de materiais: Uma abordagem logística, São Paulo: Atlas S.A., 1993.

DRUCKER, P. F.,. Innovation and entrepreneurship. Nova York: Harper Business, 2003, Inovação e espírito empreendedor, São Paulo: Pioneira Thomson. 1985.

FILHO, Gilberto Cavalcante de Albuquerque. Piscicultura Continental, Belo Horizonte, 1977.

FORD, D. et al. Managing Business Relationships. Chichester: Wiley, 2003.

FRANCISCHINI, Paulino G.; GURGEL, Floriano do Amaral. Administração de materiais e do patrimônio. Thomson Pioneira, 2002.

FRIMAN, M.; GÄRLING, T.; MILLET, B.; MATTSSON, J.; JOHNSTON, R. An analysis of international business-to-business relationships based on the commitment-trust theory. Industrial Marketing Management, v. 31, n. 5, 2002, p. 403-409.

GITOMER, Jeffrey. Livro de Vendas: princípios de excelência em vendas. São Paulo: Makron Books, 2006.

HEIDE, J. B.; JOHN, G. Do norms matter in marketing relationships? Journal of Marketing, v. 56, n. 2, p. 32-44, 1992.

KOTLER, Philip; ARMSTRONG, Gary. Princípios de Marketing - São Paulo: Prentice Hall, 2004. 
KOTLER, Philip; HAIDER, Donal; REIN, Irving. Marketink Público. Ed MaKron Books, 1994.

KOTLER, Philip. Administração de Marketing. 10 ed. São Paulo: Prentice Hall, 2000.

LAS CASAS, Alexandre Luzzi. Administração de Vendas. São Paulo: Atlas, 2005.

LAS CASAS, Alexandre Luzzi. Administração de marketing: conceitos, planejamento e aplicações à realidade brasileira. São Paulo: Atlas, 2006.

LEE, D.; PAE, J.; WONG, Y. A model of close business relationships in China (guanxi). European Journal of Marketing, v. 35, n. 1/2, 2001, p. 51-69.

LUSCH, R. F.; BROWN, J. R. Interdependency, contracting, and relational behavior in market channels. Journal of Marketing, v. 60, n. 4, p. 19-38, 1996.

MASO, Luciano. Marketing de Relacionamento: o que é? Pare que serve? Qual sua

importância para o cliente? . RACI revista de administração e ciências contábeis do IDEAU. ISSN 1809-6212 Vol. 5 - n.10 - Janeiro - Junho 2010 - Semestral

MCKENNA, Regis. Acesso Total. Rio de Janeiro: Elsevier, 2002.

OSTRENSKY, Antônio; BOEGER, Walter A. Piscicultura: Fundamentos e Técnicas de Manejo Livraria e editora agropecuária, 1998.

POZO, Amilton. Administração de recursos materiais e patrimoniais: Uma abordagem logística, 6ª edição, São Paulo (SP): Atlas, 2010.

PETER, J. Paul; DONNELLY JR, James H. Introdução ao marketing: criando valor para o cliente, Editora Saraiva, 2013.

SCHMITT, Bernd H. Gestão da experiência do cliente: uma revolução no relacionamento com os consumidores. Porto Alegre: Bookman, 2004.

SEVERINO, Antônio Joaquim. Metodologia do Trabalho Científico, Editora Cortez, 2012.

SLACK, Nigel. Administração da produção. 2. ed. São Paulo: Atlas, 2002.

SLONGO, Luiz Antônio; LIBERALI, Guilherme. Marketing de relacionamento: Estudos, cases e proposições de pesquisa. São Paulo: Atlas, 2004.

ZAND, D. E. Trust and managerial problem solving. Administrative Science Quarterly, v. 17, n. 2, p. 229-239, 1972. 